\title{
Nash Equilibria on Soft Information Control Games--Based on Banking Industry in China
}

\author{
Fei Xu \\ School of International Trade \& Economics, Guangdong University of Foreign Studies \\ Higher Education Mega Center, Guangzhou 510006, China \\ Yong Jiang (Corresponding author) \\ School of International Trade \& Economics, Guangdong University of Foreign Studies \\ Higher Education Mega Center, Guangzhou 510006, China \\ E-mail: jiangyong@gdufs.edu.cn
}

Received: October 27, 2012

Accepted: November 15, 2012

Online Published: December 23, 2012

doi:10.5430/ijfr.v4n1p84

URL: http://dx.doi.org/10.5430/ijfr.v4n1p84

The research is financed by Guangdong Excellent \& Innovative Young Scholars Cultivation Program, Guangdong Province, China. No. WYM10028, NNSFC Fund (No.71073032) and National Social Science Fund of China (10BJL026).

\begin{abstract}
In the competition of banking sector in China, to maximize the amount of soft information control is an important goal. In an n-dimensional Euclidean space, there exists Nash equilibrium for two different banks in the competition of soft information control. Keeping the same competitive strategy is the best response to each other's actions of the two banks. Further analysis is based on the incomplete information dynamic game between various branches of the same bank. The Nash equilibrium solution for the first mover is to design strategy based on market information, while the followers' optimal strategy is to imitate the first mover's policy, whatever knowledge that they may obtain.

Keywords: Nash equilibrium, Soft information, Non-cooperative game, Incomplete information dynamic game

\section{Introduction}

Traditional theory of asymmetric information explains the credit distribution problems between banks and enterprises in the financial markets. Relationships lend takes genuine and continuous soft market information as key explanatory variables, which are introduced to the income function of commercial banks. Based on the control path for soft information, scholars try to explore the current problem of asymmetric information. Soft information in bank-enterprise relationship is very valuable. This paper will consider the strategic structure relationship between banks and enterprises, by the introduction of soft information game model. Due to the different development levels of the financial markets, games between commercial banks and enterprises on soft information control are different. The main research object of this paper is dominant strategy of China's banking sector in the context of financial regulation in the economic transition period. The research will also try to find Nash equilibrium solution for large and small banks on the soft information control and existence of a stable cooperative or emulated path within branches of the same bank.

The first part of the paper is a systematic review of relevant theories. In the second part, the amount of soft information controlled by banks is taken as payoffs in the banking games, and then the paper seeks for the static Nash equilibrium of competitive strategy both in one-dimensional and n-dimensional space. China's four largest state-owned banks and other commercial banks open many branches in various regions, and they can deploy competitive strategy based on independent market information. The third part of the paper constructs a three-stage incomplete information dynamic game to analyze the balanced strategies of the various branches in the same bank with heterogeneous conditions, and the last section summarizes the conclusions of the study.
\end{abstract}




\section{Literature Review}

Some research has done on game theory and asymmetric information in the relationship between banks and enterprises in the financial markets. Game Theory is widely used in the analysis of modern financial markets, which include lemons market theory (Akerlof, 1970), information transmission (Spence, 1973) and credit distribution theory (Stiglitz, 1981). The early research on Nash equilibrium focuses on two models in monopolistic competition, known as Cournot model and Bertrand model. Dasgupta \& Maskin (1986a, 1986b) put forward the existence theorem in discontinuous games. When there is no equilibrium in consecutive game, the fine discrete barrier mapped on equilibrium will be very sensitive to the selection of division. If discrete barrier is quite insensitive to the selection in the game, more and more sophisticated barrier can be chosen for the continuous equilibrium convergence, and the limit of discrete action sequence space will converge to continuous equilibrium under appropriate continuity assumptions. Scholars of dynamic structure utilize the concept of "extended form of game" to construct a dynamic model, which clearly shows the information of the participants who take action in sequence, as well as the information that participants need in making decisions of each actions.

Other research focus on the correlation between relationship lend, soft information and market stability. Soft information is the information that cannot expressed in accurate, fixed, standard, but in an informal, fuzzy, inferential, perceptional way. It is the private information that has to be obtained when banks serve its customers, which is very costly. However, this information is the by-products for banks when they provide financial services. The relationship lend and soft information control in the financial market effectively reduce the adverse selection and moral hazard resulted from information asymmetry. Relationship lend described as a technology used in banking loan, and the lender based primarily on soft information to make lending decisions (Berger and Udell 2002, 2006). Firstly, the more solid the bank-enterprise relationship is, the better treatment that enterprises can get as the borrower, such as lower interest rates, lower collateral requirements (Berger and Udell, 1995), increase in the available loan (Petersen and Rajan, 1994;Cole, 1998) and better protection from interest rates fluctuations (Berlin and Mester,1998). Secondly, soft information control can help banks to reduce moral hazard and adverse selection that caused by information asymmetry and especially important for those small businesses who are lack of credit history or hard information. Banks with relationship lend has hold-up advantage over other banks. In the banking market of China, an important means to gain dominant position is to control maximum amount of soft information by developing a variety of competitive strategies.

Further researches discuss competition and market structure in the banking sector and related competition performance. Gwynne (1986) studied "herd behavior" of banks in lending policies in LDCs; the competition in the banking sector must take into account interactions between competition and financial stability (Allen \&Gale, 2001). Scholars in China tend to use structured SCP paradigm to analyze structure and performance of China's banking market. Ye \& $\mathrm{Li}(2008)$ believe that concentration is a measure of market forces. Concentrated markets can constraint adventurous behavior of banks and it is beneficial to the stability of banking system, but concentration is not a reliable indicator of competition. Oligopolistic market helps to maintain banking stability but that does not mean that competition should be excluded. Peng \& Lei (2010) proved that profit of banks in China experienced a general decline, while heterogeneity between banks not significantly affects the performance. Zhao (2005) relied on the Panzar-Rosse paradigm to review the market structure of China's commercial banks, and Jiang (2010) established the robustness evaluation framework of China's listed commercial banks, and test the robustness of the sample banks based on the weighted information model.

\section{Nash Equilira for Strategies between Banks in N-dimensional Linear Market}

The payoffs of banks are defined as the amount of soft information control in this game. Before an enterprise takes action and share the soft information, it will assess the strategies of competing banks from its own interests. In the long-term transactions, whether enterprise choose to share soft information depends not only on the lending policies, but also on various long-term interaction with banks, such as charges of financial operations, collateral requirements, efficiency of credit, information security management system, professional ethics of bank managers and other factors. The paper tries to alter some of the assumptions of Hotelling model, demonstrating competitive strategy equilibrium for banks in the Euclidean space.

\subsection{Assumptions in the Euclidean Space}

(1). Assuming that the market is located in the n-dimensional Euclidean space, $\mathrm{H}$ is compact convex set of bank competitive strategies in an n-dimensional Euclidean space. It is defined as a uniformly continuous real-valued function in $\mathrm{H}$. 
(2). There are numerous enterprises in the market. When enterprise face $n$ possible competitive strategies in banking competition, an enterprise can have the optimal choice with the lowest cost to share soft information with banks, assuming either space is continuous. Column vector $X^{\prime}=\left(X_{1}, X_{2}, \ldots x_{n}\right)$ represents the optimal choice for the given enterprises in each policy. For $i$ th enterprise in n-dimensional space, $x_{i n}$ is the optimal choice with the lowest cost of enterprise $i$ in $n$-dimensional space.

A column vector $x_{i n}$ represents the optimal choice of all factors by enterprise $i$ in the n-dimensional space. If the competitive strategy of bank ${ }^{j}, j \in n$, which means that soft information is shared with banks in international trade transactions, such as international remittance fee. And ${ }^{x_{i j}}$ represent the optimal international remittance rate of enterprise $i$ will accept.

(3). Assume that the ultimate goal of bank is to pursue the largest amount of soft information control.

(4). In the market, every enterprise has a different optimal choice, because the competitive strategies can be infinitely subdivided due to various factors, such as international transfer amount, the degree of openness of the market and banks, so the game has unlimited sub-strategies and there are numerous competitive strategies in the market. Assuming $\phi_{j}$ represents the competitive strategy of bank $j . \phi_{j}$ and $x_{i}$ correspond to the same dimensions, and $\phi_{j}$ is continuous and solvable.

(5). Banks can specify their own competitive strategy ${ }_{j}$ in n-dimensional space of and all enterprises has identical assessment on $\phi_{j}$. If $x_{i}=\phi_{j}$, competitive strategy formulated by the bank and optimal choice of enterprise are the same in the space, so the cost of enterprises and banks sharing soft information $d\left(x_{i}, \phi_{j}\right)$ equals to zero. If $x_{i} \neq \phi_{j}$ (at least one component of $x_{i}$ is not equal to the corresponding component in $\phi_{j}$ ), enterprises and banks have to take a positive cost. The greater the distance of any one component ${ }^{x_{i}}$ from the corresponding component in ${ }^{\phi_{j}}$, the greater the cost of soft information sharing is.

(6). In the vast majority of financial markets, it is not possible for all enterprises to obtain their optimal choice at the same time. When assessing the competitive strategies of two banks, enterprises have to trade off in n-dimensional space based on the extension of Hotelling model. The column matrix of competitive strategies for Bank A is $\phi_{A}=\zeta^{\prime}=\left(\zeta_{1}, \zeta_{2}, \ldots \zeta_{n}\right)$, and the column matrix for Bank B is $\phi_{B}=\omega^{\prime}=\left(\omega_{1}, \omega_{2}, \ldots \omega_{n}\right)$. This paper assumes that if the enterprise chooses Bank A to share the soft information, it has to give up Bank B. Then if and only if:

$$
\left\|x_{i}-\zeta\right\|_{S}<\left\|x_{i}-\omega\right\|_{S}
$$

Where,

$$
\begin{gathered}
{\left[d\left(x_{i}, \zeta\right)\right]^{2}=\left\|x_{i}-\zeta\right\|_{S}^{2}=\left(x_{i}-\zeta\right)^{\prime} S\left(x_{i}-\zeta\right)=\sum_{m, k=1, \ldots n} a_{m k}\left(x_{i m}-\zeta_{m}\right)\left(x_{i k}-\zeta_{k}\right)} \\
{\left[d\left(x_{i}, \omega\right)\right]^{2}=\left\|x_{i}-\omega\right\|_{S}^{2}=\left(x_{i}-\omega\right)^{\prime} S\left(x_{i}-\omega\right)=\sum_{m, k=1, \ldots n} a_{m k}\left(x_{i m}-\omega_{m}\right)\left(x_{i k}-\omega_{k}\right)}
\end{gathered}
$$

Equation (1) defines the principles of preferences in selecting different strategies for competitive bank, and all options are points in n-dimensional Euclidean space. Equation (2) expresses the sum of weighted squared distance $(k=m)$ and the intersection between items in each dimension $(k \neq m)$. $\left\|x_{i}-\zeta\right\|_{s}^{2}$ is the loss of choosing competitive

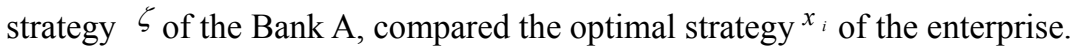

If $S$ is assumed to be symmetric positive definite matrix $\left(a_{k m}=a_{m k}\right)$ and $x_{i} \neq \zeta$, this quadratic form is greater than zero ( $S=0$ is excluded). $\left\|x_{i}-\zeta\right\|_{s}$ defines cost of the distance between point $x_{i}$ and point $\zeta$ in Euclidean space, the cost to be paid by S matrix is given. Davis \& Hinich (1968) proves that personal preferences are approximate the 
nearest available option under priority rules. When two banks compete in soft information control, $\zeta$ presents the position of Bank A's competitive in Euclidean space, while $\omega$ present the position of Bank B in space. When the optimal strategy matrix ${ }^{x_{i}}$ of enterprise $i$ has a smaller distance $\zeta$ in Euclidean space, enterprise chooses Bank A to share the soft information.

(7). $x$ is randomly selected optimal strategy of an enterprise in the market, with $S$ as its weight. Given the conditions of $S$, conditional distribution of $x$ obeys $N\left(u, \sigma^{2}\right)$. The distribution of optimal choice is symmetric distribution of mean $u$. In the n-dimensional Euclidean space, there is a hyperplane space, where each space includes the optimal choice of the enterprise. According to the assumption (1) and the numerous enterprises in the market, $f(x)$ is a continuous function in $\mathrm{S}$.

(8). If each enterprise has one unit of soft information, every enterprise must share the soft information with one of the banks. Because soft information is always confidential, an enterprise may keep sharing of soft information with a fixed bank. If two banks both have the soft information, it becomes the common information and loses market value. So a company can only choose to share soft information with only one bank.

\subsection{Analysis of Results in $\mathrm{N}$-dimensional Linear Market}

Based on the above assumptions, $\Gamma(\zeta, \omega)$ is defined as a function of the difference between the proportions of enterprises that share soft information with Bank A and proportion of those share with Bank B. For any given $\omega$, set $\{\zeta \mid \Gamma(\zeta, \omega)=0\}$ presets competitive strategy sent of Bank A and Bank B equally share the amount of information. When assumptions are meet, optimal selection strategies $x \sim N\left(u, \sigma^{2}\right)$, the probability density $f(x), u$ is the midpoint of $f(x)$. It is assumed $\Gamma(\zeta, \omega)=0$ if and only if $\|\zeta-u\|^{2}=\|\omega-u\|^{2} . \Gamma(\zeta, \omega)=0$ holds, if and only if vector $g_{\text {satisfies: }}$

$$
\begin{aligned}
& \text { I. } \int_{\{y \mid y \cdot g>0\}} f(y) d y=\int_{(y \mid y \cdot g<0)} f(y) d y ; \\
& \text { II. } \frac{1}{2}(\zeta+\omega) \in G \cdot \operatorname{and}(\zeta-\omega)(w-z)=0 \text {, and } z, w \in G
\end{aligned}
$$

The hyperplane $\mathrm{G}$ defines a set of mutually perpendicular lines between $\zeta$ and $\omega$. Vectors $g$ satisfies condition I, and $u$ is the midpoint of $f(x)$. According to condition (2), $u$ must belong to hyperplane $\mathrm{G}$. By $(\zeta-\omega) \cdot\left(\frac{\zeta+\omega}{2}-u\right)=0$,it derives the equation $\left(\zeta-\frac{\zeta+\omega}{2}\right) \cdot\left(\frac{\zeta+\omega}{2}-u\right)=0$. In Euclidean space, $\|\zeta-u\|^{2}=\|\omega-u\|^{2}$ can be obtained. Under the given condition $\omega,\{\zeta \mid \Gamma(\zeta, \omega)=0\}$ is not Nash equilibrium solution set between two banks. In a given condition $\omega \neq u, \zeta$ can occupy greater amount of soft information by approaching $\omega$. Based on the assumptions, there is an optimal choice $x_{\mathrm{i}}^{\prime}=\left(x_{1}, x_{2}, \ldots, x_{n}\right)$ of enterprise $i$ to share soft information with bank A, if and only if $\left\|x_{i}-u\right\|_{S}^{2}<\left\|x_{i}-\omega\right\|_{S}^{2}$

In which,

$$
\left\|x_{i}-u\right\|_{S}^{2}=\left(x_{i}-u\right)^{\prime} S\left(x_{i}-u\right) ;\left\|x_{i}-\omega\right\|_{S}^{2}=\left(x_{i}-\omega\right)^{\prime} S\left(x_{i}-\omega\right)
$$

If and only if: $2(x-u)^{\prime} S(\omega-u)<\|\omega-u\|_{S}^{2} ;\left\|x_{i}-u\right\|_{S}^{2}<\left\|x_{i}-\omega\right\|_{S}^{2}$ can be satisfied.

If $z=2(x-u)^{\prime} S(\omega-u)$, A choice of an enterprise can be randomly drawn from the market based on the competitive strategy of Bank A and B, the probability of Bank A's soft information sharing is: 


$$
P\left(\left\|x_{i}-u\right\|_{S}^{2}<\left\|x_{i}-\omega\right\|_{S}^{2}\right)=P\left(z<\|\omega-u\|_{S}^{2}\right)
$$

Under the given conditions $\mathrm{S}, \quad x \sim N\left(u, \sigma^{2}\right)$, where $u=E(x \mid S), \sigma^{2}$ represents covariance matrix. Random variable $z$ obeys conditional distribution $N\left(0, \sigma_{2}^{2}\right)$, if and only if:

$$
\sigma_{z}^{2}=4(\omega-u)^{\prime} S \sigma^{2} S(\omega-u)=4\|\omega-u\|_{S \sigma^{2} S}^{2}
$$

Based on by the symmetry character of normal distribution, $P(z<0)=P(z>0)=1 / 2$

For each given $\mathrm{S},\|\omega-u\|_{S}^{2}>0, P\left(z<\|\omega-u\|_{S}^{2} \mid S\right)>1 / 2$

So,

$$
P\left(z<\|\omega-u\|_{S}^{2}\right)=E_{S}\left\lfloor P\left(z<\|\omega-u\|_{S}^{2} \mid S\right)\right\rfloor>1 / 2
$$

The result is:

$$
P\left(\|x-u\|_{S}^{2}<\|x-\omega\|_{S}^{2}\right)>1 / 2
$$

In the market, the bank's dominant strategy is $\phi_{j}=u(u=E(x \mid S))$. The bank's competitive strategy has a tendency of aggregation for optmality. Therefore, there is still a competitive equilibrium for the soft information control in the multidimensional space in the banking sector. Any deviation from the equilibrium point will reduce the amount of soft information control. The average cost of the enterprises in the market under condition $\mathrm{S}$ is:

$$
E\left(\|x-\phi\|_{S}^{2} \mid S\right)=\operatorname{tr} \sum S+\|\phi-u\|_{S}^{2}
$$

With the expectation considering the diversity of S:

$E\left(\|x-\phi\|_{S}^{2}\right)=E\left(\operatorname{tr} \sum S\right)+\|\phi-u\|_{\bar{S}}^{2}$, in which $\bar{S}=E(S) ;\|\phi-u\|_{S}^{2} \geq 0$, all the banks in the market takes dominant strategies, that is $\phi_{j}=u$, When $j=A, B$, the average social cost of enterprises in sharing soft information with banks is the lowest.

Banking sector in China is facing more fierce competition on very narrow interest rate spread. Financing dependence of large enterprises on bank is declining, which poses a huge challenge to traditional operations of banks, such as asset expansion and interest margin. At the same time, small businesses have greater financial needs, and financial needs of corporate cash management, asset custody, and bond underwriting drive banks to expand their operations. The 2011 annual reports of listed banks in China reflected a convergence of banking operating income structure, which is mainly composed of net interest income, income of service fees and commissions. Further analysis of the 2011 annual report of these 16 listed commercial banks indicates that there is convergence of all banks in all aspects of operation, possibly due to the macroeconomic policies.

\section{Equilibrium of Dynamic Game with Incomplete Information between Branches of Same Bank}

\subsection{Assumptions of Dynamic Games with Incomplete Information}

Large-scale state-owned commercial banks in China have a large number of branches with the same development and competitive strategies. Each branch tries to secure more soft information to establish long-term stable relations with enterprises. Assume that the competitive strategy of $\operatorname{Bank}^{j}$ is $\phi_{j}, \phi_{j}^{j}=\left(\phi_{j 1}, \phi_{j 2}, \ldots \phi_{j n}\right)$, in which 
$\phi_{j k}, k \in n$, represents the policy for loans to small and medium-sized enterprises by the head office. $\phi_{j k}^{i}$ is the specific preferential policies of branch $i$ on loans to small and medium-sized enterprises. The more soft information branches have, more beneficial for banks to reduce the rate of bad loans. And their performance is partially evaluated by the long-term and stable customer relationship, by which bankers in branches can achieve their promotion both in status and income. This paper constructs an incomplete information dynamic game model between various branches within the same bank (Scharfstein \& Stein, 1990). Branches are heterogeneous with incomplete information. Under the assumptions of first-mover and follower, the paper tries to find the equilibrium of the dynamic game model. Basic assumptions are listed as follows:

(1). Branches have differences in resources such as geographical location, human resources, and information networks. Assuming that Branch X design a competitive strategy first, Branch Y takes action according to X's situation which makes it enjoy a larger information set.

(2). A three-stage dynamic game model is established, and bank branch has competitive strategy to establish relations in the third period with the probability $p$ of success, soft information control ${ }^{a}$, the probability of failure is $(1-p)$, and negotiation cost is ${ }^{a_{f}}$. On stage 1, bank branches can analyze the expectation of its competitive strategy. ${ }^{E_{G}}$ and $E_{B}$ denote good information and poor information, respectively. Suppose that the branches with advantages are less likely to fail:

$$
\begin{aligned}
& \operatorname{prob}\left(E_{G} \mid a_{s}, \text { advantage }\right)=\alpha, \operatorname{prob}\left(E_{B} \mid a_{f}, \text { advantage }\right)=1-\alpha \\
& \operatorname{prob}\left(E_{G} \mid a_{f}, \text { advantage }\right)=\beta<\alpha, \operatorname{prob}\left(E_{B} \mid a_{f}, \text { advantage }\right)=1-\beta
\end{aligned}
$$

Those branches with disadvantages have the same expectations, regardless the success rate of its strategy:

$$
\begin{gathered}
\operatorname{prob}\left(E_{G} \mid a_{s}, \text { disadvantage }\right)=\operatorname{prob}\left(E_{G} \mid a_{f}, \text { disadvantage }\right)=\lambda \\
\operatorname{prob}\left(E_{B} \mid a_{s}, \text { disadvantage }\right)=\operatorname{prob}\left(E_{B} \mid a_{f}, \text { disadvantage }\right)=1-\lambda
\end{gathered}
$$

When two branches are at disadvantages, their competitive strategy is independent, with probability of $\lambda^{2}$ to obtain good information on competitive strategy. When two branches are at advantages, their information generated by competition strategies is completely relevant.

(3). Probability to obtain good information for branches with advantage and disadvantage is identical:

$$
\operatorname{prob}\left(E_{G} \mid \text { advantage }\right)=\operatorname{prob}\left(E_{G} \mid \text { disadvantage }\right), \text { then: } \lambda=p \alpha+(1-p) \beta
$$

(4). The type of branch cannot be pre-determined. Bank branch has the probability of $\delta$ to be bank with advantages and $1-\delta$ to be bank with disadvantages. Based on Bayes' rule,

$$
\begin{gathered}
\operatorname{prob}\left(a_{s} \mid E_{G}\right)=\mu_{G}=\frac{[\delta \alpha+(1-\delta) \lambda]}{\lambda} \cdot p ; \operatorname{prob}\left(a_{s} \mid E_{B}\right)=\mu_{B}=\frac{[\delta(1-\alpha)+(1-\delta)(1-\lambda)]}{1-\lambda} \cdot p \\
\text { And: } \mu_{G} a_{s}+\left(1-\mu_{\mathrm{G}}\right) a_{f}>0>\mu_{B} a_{s}+\left(1-\mu_{B}\right) a_{f}
\end{gathered}
$$

(5). Assuming that the final objective of bank branch is to obtain promotion and performance awards $U^{i}, i=X, Y$, the only information is that the probability of banks being branch with advantage and branch with disadvantage are 
$\delta$ and $1-\delta$, respectively. Branches $\mathrm{X}$ and $\mathrm{Y}$ would adjust the probability of branch with advantage as $\hat{\delta}$, and this probability is directly related to the promotion and performance incentives, the greater $\hat{\delta}$ is, the greater chance for the promotion and the more performance awards are. Utility function branch can be assumed: $U^{i}=U^{i}(\hat{\delta}), i=\{X, Y\}$, which satisfies $\frac{\partial U^{i}}{\partial \hat{\delta}^{i}}>0, \hat{\delta}$ depends on the capabilities of bank branch to screen market information and immediate the strategy.

\subsection{Analysis of Results in Dynamic Games of Bank Branches}

Based on the above assumptions and X's first move in implementation the competition policy, the equilibrium for $\mathrm{Y}$ in the second phase should be discussed. Assume $\beta=1-\alpha, p=\frac{1}{2}$, so $\lambda=\frac{1}{2}$. If $\mathrm{X}$ and $\mathrm{Y}$ are the branches in advantages, $\mathrm{X}$ and $\mathrm{Y}$ can be set (advantage, disadvantage), (disadvantage, advantage), (disadvantage, disadvantage).

Bank X, Y have probability of (disadvantage, advantage) $\delta(1-\delta)$. In the third period, the successful competitive strategy is $a_{s}$. Branch X generates information set $E_{B}$, the probability of the information set generated branch $\mathrm{Y}$ is $\operatorname{prob}\left(E_{B}, E_{G} \mid a_{s}\right)=\frac{1}{2} \alpha$. So the adjusted possibility could be:

$$
\begin{gathered}
\hat{\delta}^{Y}\left(E_{G}, E_{B}, a_{f}\right)=\hat{\delta}^{Y}\left(E_{B}, E_{G}, a_{s}\right)=\frac{2 \delta \alpha}{1+\delta} ; \hat{\delta}^{Y}\left(E_{B}, E_{G}, a_{f}\right)=\hat{\delta}^{Y}\left(E_{G}, E_{B}, a_{f}\right)=\frac{2 \delta(1-\alpha)}{1+\delta} \\
\hat{\delta}^{Y}\left(E_{B}, E_{B}, a_{S}\right)=\hat{\delta}^{Y}\left(E_{G}, E_{G}, a_{f}\right)=\frac{2 \delta(1-\alpha)(1+\delta)}{4 \delta(1-\alpha)+(1-\delta)^{2}} ; \hat{\delta}^{Y}\left(E_{B}, E_{B}, a_{f}\right)=\hat{\delta}^{Y}\left(E_{G}, E_{G}, a_{s}\right)=\frac{2 \delta \alpha(1+\delta)}{4 \delta \alpha+(1-\delta)^{2}}
\end{gathered}
$$

Then we can proof:

$$
\begin{aligned}
& \hat{\delta}^{Y}\left(E_{G}, E_{B}, a_{s}\right) \operatorname{prob}\left(a_{s} \mid E_{G}, E_{B}\right)+\hat{\delta}^{Y}\left(E_{G}, E_{B}, a_{f}\right) \operatorname{prob}\left(a_{f} \mid E_{G}, E_{B}\right)< \\
& \hat{\delta}^{Y}\left(E_{G}, E_{G}, a_{s}\right) \operatorname{prob}\left(a_{s} \mid E_{G}, E_{B}\right)+\hat{\delta}^{Y}\left(E_{G}, E_{G}, a_{f}\right) \operatorname{prob}\left(a_{f} \mid E_{G}, E_{B}\right)
\end{aligned}
$$

Whether branch $\mathrm{Y}$ is branch with advantages or not, when branch $\mathrm{X}$ first implement the competition policy, branch $\mathrm{Y}$ would not select policy on its own basis of information, but imitate the strategy of branch X. So its adjusted probability is always better. When $\mathrm{X}$ and $\mathrm{Y}$ choose their competition policy, branch $\mathrm{Y}$ has the probability of $\delta$ to be branch with advantage. If the probability of branch's type is fixed, it can be tested that whether branch $\mathrm{Y}$ will produce higher gains with any deviation from strategy imitation. When branch $\mathrm{X}$ obtain good information in the first stage and choose to implement competitive strategies, the observed information set of branch $\mathrm{Y}$ is ${ }_{G}$, the adjusted probability is:

$$
\begin{aligned}
& \hat{\delta}^{Y}\left(E_{G}, E_{B}, a_{s}\right) \operatorname{prob}\left(a_{s} \mid E_{G}, E_{G}\right)+\hat{\delta}^{Y}\left(E_{G}, E_{B}, a_{f}\right) \operatorname{prob}\left(a_{f} \mid E_{G}, E_{G}\right) \\
& =\frac{2 \delta(1-\alpha)}{1+\delta} \cdot \frac{4 \delta \alpha+(1+\delta)^{2}}{4 \delta+2(1-\delta)^{2}}+\frac{2 \delta \alpha}{1+\delta} \cdot \frac{4 \delta(1-\alpha)+(1-\delta)^{2}}{4 \delta+2(1-\delta)^{2}}<\delta
\end{aligned}
$$

If branch $\mathrm{Y}$ choose not to implement the competitive strategy, then:

$$
\begin{aligned}
& \hat{\delta}^{Y}\left(E_{G}, E_{B}, a_{s}\right) \operatorname{prob}\left(a_{s} \mid E_{G}, E_{B}\right)+\hat{\delta}^{Y}\left(E_{G}, E_{B}, a_{f}\right) \operatorname{prob}\left(a_{f} \mid E_{G}, E_{B}\right) \\
& =\frac{\delta(1-\alpha)}{1+\delta}+\frac{\delta \alpha}{1+\delta}=\frac{\delta}{1+\delta}<\delta
\end{aligned}
$$

When branch X enforce competition policy in the first stage, imitating branch X's competitive strategy can earn 
higher earnings regardless information obtained by branch Y is good or bad. On the one hand, imitating branch X's competitive strategy can increase the possibility of promotion and performance awards. On the other hand, imitation on the homogeneous strategy can reduce the risk of punishment arouse by mistake. Therefore, regardless of branch $\mathrm{Y}$ is branches with advantage or disadvantage, imitating the strategy is a dominant strategy.

Now strategy of branch $\mathrm{X}$ is considered, $\hat{\delta}^{X}$ is the adjusted probability of branch $\mathrm{X}$ to be a bank with advantages, by Bayesian formula,

$$
\begin{gathered}
\hat{\delta}^{X}\left(E_{G}, a_{s}\right)=\hat{\delta}^{X}\left(E_{B}, a_{f}\right)=\frac{2 \delta \alpha}{2 \delta \alpha+1-\delta} \\
\hat{\delta}^{X}\left(E_{G}, a_{f}\right)=\hat{\delta}^{X}\left(E_{B}, a_{s}\right)=\frac{2 \delta(1-\alpha)}{2 \delta \alpha+1-\delta}
\end{gathered}
$$

based on the above results:

$$
\begin{gathered}
\operatorname{prob}\left(a_{s} \mid E_{G}\right)=\mu_{G}=\delta \alpha+\frac{1}{2}(1-\delta) \\
\operatorname{prob}\left(a_{s} \mid E_{B}\right)=\mu_{B}=\delta(1-\alpha)+\frac{1}{2}(1-\delta)
\end{gathered}
$$

the following inequalities can be obtained:

$$
\begin{gathered}
\hat{\delta}^{X}\left(E_{G}, a_{s}\right) \mu_{s}+\hat{\delta}^{X}\left(E_{G}, a_{f}\right)\left(1-\mu_{s}\right)>\hat{\delta}^{X}\left(E_{B}, a_{s}\right) \mu_{s}+\hat{\delta}^{X}\left(E_{B}, a_{f}\right)\left(1-\mu_{s}\right) \\
\hat{\delta}^{X}\left(E_{B}, a_{s}\right) \mu_{f}+\hat{\delta}^{X}\left(E_{B}, a_{f}\right)\left(1-\mu_{f}\right)>\hat{\delta}^{X}\left(E_{G}, a_{s}\right) \mu_{f}+\hat{\delta}^{X}\left(E_{G}, a_{f}\right)\left(1-\mu_{f}\right)
\end{gathered}
$$

The left side of inequality means that branch $\mathrm{X}$ observes good information and chooses to implement competitive strategies. The adjusted possibility of this situation is greater than the adjusted probability of "branch X observe good information, but choose not to perform competitive strategy". The inequality indicates that when branch X observe bad information, not enforcing competition strategy is a more profitable decision. Therefore, for branch $\mathrm{X}$ who takes first action, the optimal strategy is based on market information to make decisions whether to execute a competitive strategy.

Based on the above analysis, regional branches of the same bank face internal competitions. The possibility of promotion and performance awards are determined by whether branches are at advantage or not. Developing successful competitive strategies can help banks to obtain more soft information control and to establish long-term stable cooperative relations. Whether the branch is at advantage or disadvantage, first-mover branch make decisions on the information obtained from the market, and dominant strategy of following-up branch is to imitate the action of the first mover. In a competitive environment, two branches eventually reach the same equilibrium, and none of them has an incentive to deviate from the point.

\section{Conclusion}

When large banks possess more privileges on soft information resources, small banks only occupies a limited amount of soft information due to capital market constraints. Large banks may extrude small banks. However, when small banks obtain fund, human capital, government support, they will rapidly expand the original amount of soft information control and their strategy will continue to approach the large banks. The equilibrium of the game on loan strategy is still that two banks hold the same loan interest rate, and split the amount of soft information in the market. If assumptions are relaxed, games of rivalry between banks on soft information control can be built in a Euclidean space, which proves that the optimal choice of banks is to develop competitive strategy imitating other banks. The equilibrium is to take neutral competitive strategy with minimum cost of social delivery on soft information. There are information asymmetries in the competition between heterogeneous branches of the same bank. If any branch deviate from the equilibrium and implement innovative competitive strategy, other branches would imitate the strategy. At equilibrium, no branch would like to develop new financial products and services. When a branch deviates from the equilibrium point, the other branches would follow the same competitive strategy in the next stage and competitive equilibrium will return to the original. 


\section{References}

Akerlof, G. A. (1970). The Market for "Lemons": Quality Uncertainty and the Market Mechanism. Quaterly Journal of Economics, 84(3), 488-500. http://dx.doi.org/10.2307/1879431

Allen, F., \& Gale, D. M. (2001). Comparing Financial Systems (1st ed.). MIT Press: Cambridge. (Chapter 2).

Berger, A. N., \& Udell, G. F. (1995). Relationship Lending and Lines of Credit in Small Firm Finance. Journal of Business, 68(3), 351-381.

Berger, A. N., \& Udell, G. F. (2002). Small Business Credit Availability and Relationship Lending: The importance of Bank Organisational Structure. Economic Journal, 114(447), F32-F53. http://dx.doi.org/10.1111/1468-0297.00682

Berger, A. N., \& Udell, G. F. (2006). A More Complete Conceptual Framework for SME Finance. Journal of Banking and Finance, 30(11), 2945-2966. http://dx.doi.org/10.1016/j.jbankfin.2006.05.008

Berlin, M., \& Mester, L. J. (1998). On the Profitability and Cost of Relationship Lending. Journal of Banking and Finance, 22(6), 873-897. http://dx.doi.org/10.1016/S0378-4266(98)00033-8

Cole, R. (1998). The Importance of Relationships to the Availability of Credit. Journal of Banking and Finance, 22(6), 959-977. http://dx.doi.org/10.1016/S0378-4266(98)00007-7

Dasgupta, P., \& Maskin, E. (1986a). The Existence of Equilibrium in Discontinous Economic Games, I: Theory. Review of Economic Studies, 53(1), 1-26. http://dx.doi.org/10.2307/2297588

Dasgupta, P., \& Maskin, E. (1986b). The Existence of Equilibrium in Discontinous Economic Games, II: Applications. Review of Economic Studies, 53(1), 28-42.

Davis, O. A., \& Hinich, M. J. (1968). On the Power and Importance of the Mean Preference in a Mathematical Model of Democratic Choice. Public Choice, 5(1), 59-72. http://dx.doi.org/10.1007/BF01718684

Gwynne, S. (1986). Selling Money (1st ed.). New York: Penguin Books. (Chapter 2)

Hotelling, H. (1929). Stability in Competition. Economic Journal, 39(153), 41-57. http://dx.doi.org/10.2307/2224214 Jayaratne, J., \& Wolken, J. (1999). How important are small banks to small business lending?: New Evidence from a Survey of Small Firms. Journal of Banking and Finance, 23(2), $427-458$. http://dx.doi.org/10.1016/S0378-4266(98)00085-5

Jiang, Y. (2011). The Stability Assessment of Listed Commercial Bank in China. Science Technology and Engineering, 3, 669-673.

Peng, H., \& Lei, Z. (2010). The Empirical Research of the Relationship of Deregulation and the Competition of Chinese Banking. Nankai Economic Studies, 2, 80-97.

Petersen, M. A., \& Rajan, R. G. (1994). The Effect of Credit Market Competition on Lending Relationships. Quarterly Journal of Economics, 110(2), 407-443. http://dx.doi.org/10.2307/2118445

Scharfstein, D. S., \& Stein, J. C. (1990). Herd Behavior and Investment. American Economic Reviews, 80(3), 465-479. http://dx.doi.org/10.1257/aer.90.3.705

Spence, M. (1973). Job Market Signaling. Quaterly Journal of Economics, 87(3), 355-374. http://dx.doi.org/10.2307/1882010

Stiglitz, J. E., \& Weiss, A. (1981). Credit Rationing in Markets with Imperfect Information. American Economic Review, 71(3). 393-410.

Ye, L. W., \& Li, J. J. (2008). Market Structure, Credit Behavior and Banking Stability. Economic Perspectives, 5, 59-64.

Zhao, Z. G., Peng, Q., \& Zou, K. (2005). The Analysis of Market Competition Structure of Banking Industry of China_The Research Based on Panzar-Rosse Model. Statistical Research, 22(6), 69-73. 